\title{
Reseña del libro Noches de sano esparcimiento. Estado, católicos y empresarios en la censura al cine
} en Argentina I955-I973, de Fernando Ramírez Llorens (2016).

Buenos Aires: Libraria, 248 pp. ISBN 978-987-3754-I2-8

\section{Cecilia Carril}

Facultad de Humanidades y Ciencias-FHUC Universidad Nacional del Litoral-UNL

Noches de sano esparcimiento... es una propuesta original y sumamente creativa. En Argentina la censura, especialmente en el campo cinematográfico, ha sido abordada en referencia casi exclusiva a la experiencia dictatorial iniciada en marzo de 1976 , pero sigue siendo un aspecto que demanda mayor centralidad en los análisis referidos al período de democracias tuteladas y dictaduras militares iniciado en 1955.

El libro de Fernando Ramírez Llorens, basado en el trabajo de Tesis doctoral (UBA, 20I5) y publicado en coedición con la Biblioteca ENERC/INCAA a partir del $I^{\circ}$ Concurso Nacional y Federal de Estudios sobre Cine Argentino, refleja un arduo y exhaustivo trabajo de análisis documental e interpretaciones teóricas, adentrándonos en el entramado de relaciones entablado entre actores estatales, católicos y empresariales en el campo cinematográfico argentino entre 1955 y I973, específicamente en los posicionamientos asumidos y las estrategias adoptadas en torno a la censura.

$\mathrm{Su}$ análisis evita caer en una historia hecha por grandes hombres, situando sus acciones y proyectos en el marco de procesos socioculturales más amplios. Noches de sano esparcimiento... posibilita pensar la historia sociocultural de nuestro pasado reciente en términos de transición, brindando elementos para identificar continuidades y rupturas en la larga y mediana duración. La obra permite 
entablar un profundo y enriquecedor diálogo — necesario, por otra parte- con los estudios de cine realizados en base a la filmografía local producida por fuera del centro de poder nacional, ofreciendo un sólido marco teórico-metodológico para el estudio de las políticas estatales provinciales y para indagar la producción y circulación de films desde la problematización de la temática de la censura, sus prácticas y las formas en que era considerada por la sociedad.

Un caso paradigmático en la historia del cine santafesino es el filme Los cuarenta cuartos, un mediometraje documental realizado en 1962 por Juan Fernando Oliva (egresado del Instituto de Cinematografía de la Universidad Nacional del Litoral), que presenta las dificultades de acceso a la vivienda para trabajadores de escasos recursos y las condiciones de vida en un conventillo céntrico de la ciudad de Santa Fe (Argentina) en los primeros años de la década del '6o. Enviado a la Dirección Nacional de Cultura para ser exhibido en la Muestra Anual del Cortometraje, fue secuestrado y prohibido por Decreto 79I del Poder Ejecutivo Nacional del gobierno de facto del presidente José María Guido, con fecha 30 de enero de 1963. El marco interpretativo construido por Ramírez Llorens y su concepción de la censura como espacio de negociación y conflicto basado en la lucha por la legitimación de determinados usos sociales del cine,nos posibilita comprender y explicar hechos como este desde una mirada compleja que cruza una perspectiva histórica con las peculiaridades de un análisis cultural.

El autor propone un recorrido básicamente cronológico, caracterizando las formas que adoptan las prácticas de producción, exhibición y distribución de la industria cinematográfica argentina e identificando los cambios en las relaciones de fuerza en el campo cinematográfico, sin desconocer las transformaciones en el campo cultural y religioso ni sus vinculaciones con procesos socioeconómicos y políticos del período. Desde un análisis en profundidad, basado en la teoría bourdesiana, se abordan las estrategias adoptadas por cada uno de los agentes colectivos, dando cuenta de la diversidad de posiciones existentes en su interior y de los cambios en su capacidad de inserción en las estructuras estatales.

Atravesando el corpus de reflexiones sobre la censura - jurídicas y periodísticas - producidas en el período, el Ramírez Llorens reconstruye los diversos posicionamientos asumidos en torno a los usos del cine, adentrándonos en el debate sobre la legitimidad de la censura y dando cuenta de la multiplicidad de mecanismos de censura existentes, algunos más institucionalizados y otros improvisados en las circunstancias. Y aquí hay que destacar uno de los mayores logros del autor, el de matizar ciertas afirmaciones referidas al funcionamiento 
del campo cultural del período y a la relación cultura-política de acuerdo a la especificidad del campo cinematográfico. Dos afirmaciones resultan centrales en este planteo: la censura no era exclusivamente estatal y no se ejerció solo a través de la coerción. En este sentido, resulta pertinente discutir, como lo hace muy claramente el autor, las políticas de prohibición y las políticas de promoción como dos caras de la misma moneda y pensar la función prescriptiva del censor y la función orientativa del crítico de cine en términos de continuidad ideológica.

Los primeros cinco capítulos del libro están dedicados a caracterizar el accionar del Estado, la Iglesia y los empresarios cinematográficos, sus proyectos divergentes y las concepciones en que se basan (de orden, morales y comerciales). Leídos en conjunto, proporcionan una explicación muy clara de las tensiones y luchas que supuso el proceso de construcción de consenso en torno al uso social del cine como "sano esparcimiento", es decir, como un entretenimiento moralmente aceptable, que colabore con la legitimidad del orden y sea a la vez económicamente sustentable.Los últimos dos capítulos del libro refieren a la crisis de este acuerdo entre 1966 y 1973, entendida como un cambio de fuerzas al interiordel campo cinematográfico, cuando se impone la perspectiva católica en la configuración de la censura y el Estado se apropia de la censura en un proceso de profesionalización y burocratización. En cada uno de los capítulos se evidencia un serio trabajo de construcción de datos a partir de la problematización de categorías analíticas muy empleadas en los más diversos estudios, como modernidad y tradición, logrando definir otras que resultan sumamente operativas para la temática abordada, por ejemplo censura consultiva, inclusión marginal o vigilancia social.

El capítulo I se centra en los cambios en materia de política cinematográfica que se producen a partir de 1957 con el Decreto Ley $62 / 57$, producto de la influencia de un sector de cinéfilos y cineastas renovadores nucleados en cineclubes locales y fortalecidos a partir de las universidades y el Fondo Nacional de las Artes. El capítulo 2 indaga en la intervención en el cine impulsada por grupos católicos, conceptualizándola como paternalismo autoritario, orientado a establecer las cinematografías menos conflictivas para la moral católica. El capítulo 3 analiza la confluencia de intereses entre los grupos católicos y el poder político-militar y explica de qué manera se articulan los objetivos moral y comercial en el concepto de "sano esparcimiento», sin dejar de lado las estrategias de resistencia al control de la exhibición. En el capítulo 4 se precisa en qué sentido puede hablarse de experiencias cinematográficas independientes en el contexto abordado y cómo circulan de manera disociada del circuito comercial, 
abordando el complejo juego de intereses que median las relaciones entre exhibidores y productores frente a las políticas de protección y fomento. En el capítulo 5 se hace referencia a la respuesta del gobierno militar que asume en 1955 frente a la producción cinematográfica realizada por fuera de las estructuras estatales e industriales, aludiendo además a las negociaciones que el Estado entabla con los empresarios para evitar el boicot de esas expresiones cinematográficas.

El capítulo 6 explica los límites que en los hechos encuentra la experiencia represiva de control de la exhibición, señalado los condicionamientos impuestos por la participación de empresas de capitales extranjeros. Finalmente, analizando los informes de espionaje de la Dirección de Inteligencia de la Provincia de Buenos Aires (DIPBA) —abierta al público desde el año 2003, custodiada y gestionada por la Comisión Provincial de la Memoria-, el autor realiza en el capítulo 7 un estudio de carácter exploratorio que da cuenta de la articulación funcional entre el control nacional de la producción-exhibición y el control local de la comunidad.

Ramírez Llorens concluye que, independientemente de los cambios en el régimen político y la alternancia de gobiernos civiles y dictaduras cívicomilitares, puede constatarse la existencia de una matriz social autoritaria. Así, deja en claro que entre 1955 y 1973 la censura no se ejerce de manera monolítica, ni es implementada de forma exclusivamente jerarquizada o autoritaria. Se sostiene más bien sobre una red de relaciones sociales y en este sentido, una afirmación del autor resulta esclarecedora: la censura no es algo que le "ocurrió a la sociedad", es algo que la sociedad misma produjo y reprodujo. Noches de sano esparcimiento... invita a pensar periodizaciones que contemplen la especificidad del objeto estudiado y sus particularidades en diversos espacios. Convoca a discutir en torno a las políticas estatales de producción y distribución cinematográfica, así como su relación con las políticas privadas de comercialización. Incita en definitiva a repensar cierto sentido común y ciertos estereotipos construidos en torno a la censura y sus mecanismos de imposición. Bienvenido es el debate abierto por el enriquecedor análisis de Ramírez Llorens y a él intentamos contribuir con esta reseña. Como parte de la sociedad, queda en nosotros involucrarnos. 